\title{
Frozen Tissue Examination: Is It really no Longer of Use in Parathyroid Surgery? Single-center Retrospective Study on 97 Patients treated by minimally Invasive Approach
}

\author{
${ }^{1}$ Thomas Furderer, ${ }^{2}$ Nicolas Bouviez, ${ }^{3}$ Brice Paquette, ${ }^{4}$ Gerard Landecy, ${ }^{5}$ Bruno Heyd \\ ${ }^{6}$ Gabriel Vienney, ${ }^{7}$ Zaher Lakkis, ${ }^{8}$ Mael Tauziede
}

\begin{abstract}
Introduction: Surgery, by minimally invasive approach, has become the gold standard in the treatment of primary hyperparathyroidism. However, the preoperative and intraoperative examinations to be performed are still subject to debate. The frozen tissue examination of the parathyroidectomy specimen is often criticized, as it is deemed difficult and noninformative in case of multiglandular disease. The primary objective was to study the result of the frozen tissue examination and its benefit in the operative strategy in minimally invasive surgery.
\end{abstract}

Materials and methods: This is a single-centre retrospective descriptive study on patients who underwent surgery for primary hyperparathyroidism between January 2011 and September 2013 at Besançon Centre Hospitalier Régional Universitaire (CHRU) [Regional University Hospital Center]. Inclusion criteria consisted of: At least one contributory preoperative imaging test, a focused approach, and an intraoperative frozen tissue examination with microscopic analysis of the surgical specimen.

Results: A total of 157 patients were treated for hyperparathyroidism and 97 were enrolled in the study. The mean age was $62.3 \pm 13.7$ years, mean serum calcium was $2.81 \pm$ $0.24 \mathrm{mmol} / \mathrm{L}$ and the mean parathyroid hormone $(\mathrm{PTH})$ level was $175 \pm 120 \mathrm{pg} / \mathrm{mL}$. Around 53 patients (54.6\%) had concordant scintigraphic and ultrasound examinations while 20 patients $(20.6 \%)$ had an isolated contributory scintigraphic examination, 21 patients (21.6\%) had an isolated contributory cervical ultrasound and 3 patients had discordant examinations. The sensitivity of the preoperative imaging in case of concordance was $84.9 \%$ for the location of the diseased gland, and $92.4 \%$ for its lateralization. The sensitivity to ultrasound alone and scintigraphy alone was $61.9 \%$ and $65 \%$ respectively. Nearly 23 false positive imaging results were found in which 11 were corrected during surgery by the surgeon based on the macroscopic appearance. The frozen tissue examination of the surgical specimen changed the surgical strategy in 12 cases (12.4\%): Six results of normal parathyroid gland (50\%), four results of thyroid tissue $(33.3 \%)$, and two cases of hyperplastic gland $(16.7 \%)$. The results of the frozen tissue examination thus led to 12 exploratory cervicotomies, which revealed three ipsilateral adenomas (25\%), six contralateral adenomas, and

\footnotetext{
${ }^{1,4}$ Investigator, ${ }^{2,3,6-8}$ Reader, ${ }^{5}$ Professor

1-5,7 Department of Liver Transplant, General and Digestive Surgery Unit, The University Hospital of Besançon, Besançon, France

${ }^{6,8}$ Department of Pathology, The University Hospital of Besançon, Besançon, France
}

Corresponding Author: Thomas Furderer, Investigator Department of Liver Transplant, General and Digestive Surgery Unit, The University Hospital of Besançon, Besançon, France Phone: +0667001308, e-mail: thomasfurderer@hotmail.fr one adenoma included in the thyroid lobe, and enabled the surgeon to perform two subtotal parathyroidectomies for parathyroid hyperplasia. The mean duration of the frozen tissue examination was $24.2 \pm 8.6$ minutes and the cure rate is $100 \%$ for the population treated by minimally invasive approach.

Conclusion: In our experience, the frozen tissue examination enabled the surgeon to intraoperatively correct 12 erroneous imaging diagnoses, including two cases of parathyroid hyperplasia and thus to continue the exploration of other glands and immediately carry out the appropriate treatment. This is an interesting technique, but it is conditioned by the pathologist's expertise.

Keywords: Frozen section exam, Hyperparathyroidism, Parathyroidectomy.

How to cite this article: Furderer T, Bouviez N, Paquette $B$, Landecy G, Heyd B, Vienney G, Lakkis Z, Tauziede M. Frozen Tissue Examination: Is It really no Longer of Use in Parathyroid Surgery? Single-center Retrospective Study on 97 Patients treated by minimally Invasive Approach. World J Endoc Surg 2017;9(2):55-60.

\section{Source of support: Nil}

Conflict of interest: None

\section{INTRODUCTION}

Laboratory tests for hyperparathyroidism are wellcodified and recommendations of learned societies are validated. ${ }^{1}$ However, the imaging tests, the treatment, and the intraoperative control arrangements are still being debated. There are two different surgical strategies: Exploratory cervicotomy with visualisation of the four glands or focused minimally invasive surgical approach $^{2,3}$ enabling the visualization of one or two glands. However, the lack of visualization of the four glands makes it impossible to rule out multiglandular involvement and, in particular, the rare case of double adenomas, and because of that, some authors recommend systematic intraoperative PTH assays (intraoperative assay of the PTH or tissue PTH). While experts condemn the utility of the frozen tissue examination of the surgical specimen in parathyroid disease, as it is deemed difficult and ineffective in the event of multiglandular disease, ${ }^{4}$ we continue to perform it because we feel that the pathologist provides a sufficiently precise, rapid and committed response (adenoma or hyperplasia or normal gland) for a change in surgical management intraoperatively. 
The objective of our study is to assess the performance and results of the frozen tissue examination in minimally invasive surgery for primary hyperparathyroidism, and its role in the change in surgical strategy.

\section{MATERIALS AND METHODS}

This is a single-centre retrospective descriptive study conducted in the University Hospital Centre of Besançon between January 2011 and September 2013.

Laboratory tests for primary hyperparathyroidism included at least a corrected serum calcium, PTH, 25-hydroxy vitamin D (performed in different laboratories with varying standards), creatinine level, cervical ultrasound, MIBI dual-phase or dual isotope scintigraphy (I123/MIBI). The ultrasound and scintigraphic imaging examinations were not all performed by the same operators, and there was no systematic review by the surgeon for technical reasons. Urine calcium levels were not measured systematically.

\section{Inclusion Criteria}

Inclusion criteria were the presence of a primary hyperparathyroidism confirmed by laboratory tests, for which the preoperative assessment was complete with at least one of the imaging examinations identifying a diseased gland and for which a minimally invasive surgery had been performed.

\section{Exclusion Criteria}

The exclusion criteria comprised patients who had not had two preoperative imaging tests or who had undergone a bilateral exploratory cervicotomy right away.

The surgery consisted of a median mini cervicotomy under general anesthesia with investigation of the gland located by imaging first. If the macroscopic appearance was consistent with a parathyroid adenoma, the gland was resected and sent for an anatomopathological frozen tissue examination. The duration of the frozen tissue examination was measured from the moment the surgical specimen left for pathological anatomy to the moment when the results were communicated to the surgeon. If the frozen tissue examination showed the presence of adenoma, the exploration was stopped. However, in the absence of adenoma on the frozen tissue examination, the cervical exploration was first conducted on the same side and then, if necessary, on the opposite side. The macroscopic anatomopathological criteria for adenoma selected by the surgeon were piriform solitary tumor appearance, increase in weight and size, and the presence of a rim with a single vascular pedicle of yellowish-brown color and homogeneous appearance, and were confirmed by the pathologist. The microscopic examination had to show hypercellularity composed of chief and oxyphil cells with nuclear rearrangements, few mitoses, without adipose stroma and atrophy of the periadenomatous residual tissue. While the macroscopic appearance of hyperplastic gland was often that of lobulated involvement, microscopy showed a diffuse or lobulated involvement and the presence of a trabecular acinar architecture with a dense stroma containing adipocytes.

The corrected serum calcium was measured on the 1st day after the surgery, and the patient was re-examined during a follow-up consultation at 1 month postoperatively, with corrected serum calcium and PTH tests.

We studied the age, sex, preoperative serum calcium and $\mathrm{PTH}$, preoperative imaging, the location of the adenoma, the macroscopic appearance of the lesion by the surgeon, the duration of the frozen tissue examination (legal time of 20-30 minutes in the French pathological anatomy and cytology report of April 12, 2012), the result of the frozen tissue examination, the intraoperative change in surgical strategy, the final anatomopathological findings, the corrected serum calcium on the 1st day and then the corrected serum calcium and PTH at 1 month.

The statistical analysis performed was descriptive, with calculation of means, medians, standard deviations and sensitivities and specificities for the preoperative examinations.

\section{RESULTS}

Of the 157 patients treated for hyperparathyroidism during this period, 97 were enrolled in the study (Flow Chart 1).

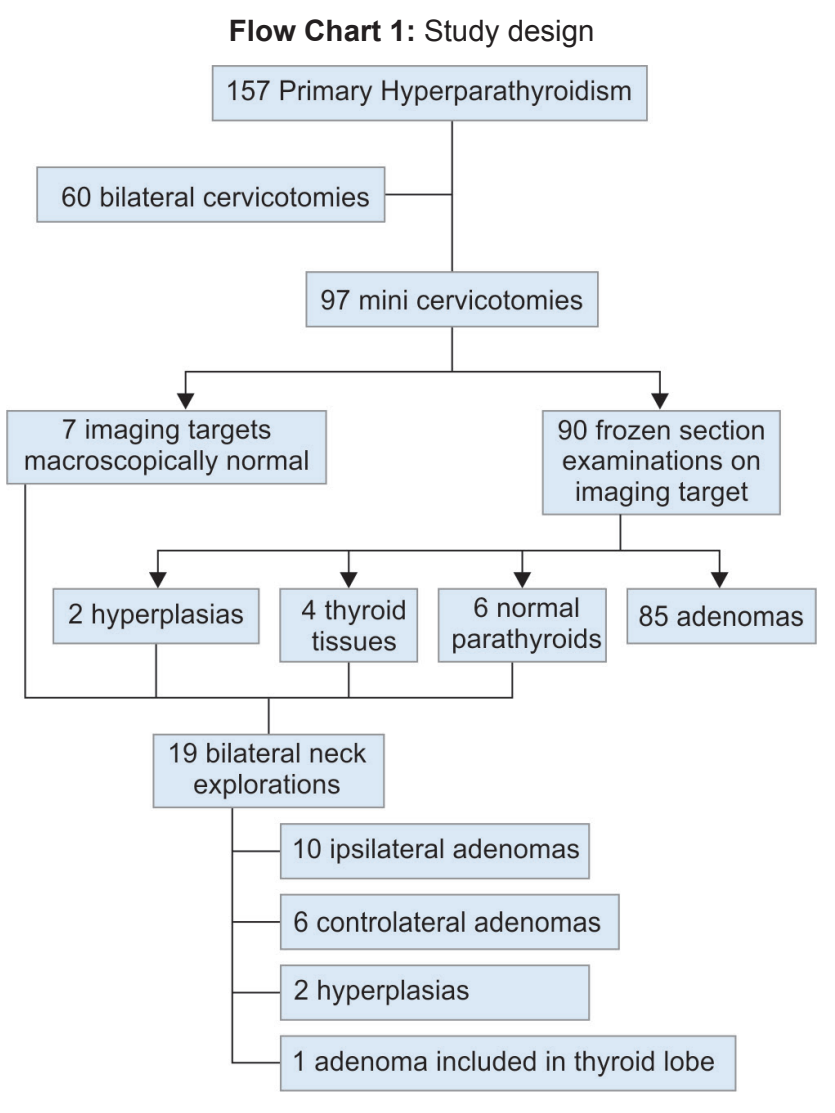


Frozen Tissue Examination: Is It really no Longer of Use in Parathyroid Surgery? Single-center Retrospective Study

Table 1. Population presentation

\begin{tabular}{ll}
\hline & Number of patients (97) \\
\hline Mean age (years) & $62.3 \pm 13.7(21-88)$ \\
Sex ratio (Female/Male) & 4.75 \\
Mean calcemia (mmol/L) & $2.81 \pm 0.24(2.53-3.52)$ \\
Mean Parathormone $(\mathrm{pg} / \mathrm{ml})$ & $175 \pm 120(56-514)$ \\
\hline
\end{tabular}

Around $17.4 \%$ were men and $82.6 \%$ were women whose average age was $62.3 \pm 13.7$ years. The mean serum calcium level was $2.81 \pm 0.24 \mathrm{mmol} / \mathrm{L}$ and the mean PTH level was $175 \pm 120 \mathrm{pg} / \mathrm{mL}$ (Table 1 ).

Of the 97 patients, 53 patients ( $54.6 \%$ ) had concordant scintigraphic and ultrasound examinations; 20 patients (20.6\%) had an isolated contributory scintigraphic examination; $21(21.7 \%)$ had an isolated contributory cervical ultrasound. Three patients had discordant examinations (ultrasound and scintigraphic targets concerned opposite sides) for which the scintigraphic target was chosen for a focused approach.

The location of the adenoma was confirmed in 45 patients $(84.9 \%)$ when imaging tests were concordant (Table 2). However, the location of the adenoma was confirmed in only 13 patients $(65 \%)$ when the scintigraphy was contributory in isolation and in 13 patients $(61.9 \%)$ when the neck ultrasound was contributory in isolation. The scintigraphic target was confirmed in all three cases of discordant imaging (3.1\%). So there were 23 false positives $(23.7 \%)$ of the preoperative imaging. The detailed examination of these false positive imaging results helped find, after further cervical exploration, 14 adenomas located on the same side as the imaging target (P3-P4 error) of which, 11 were corrected macroscopically by the surgeon (macroscopically normal gland of lenticular shape, 4 to $6 \mathrm{~mm}$ in size, brownish, in normal anatomic position): Six contralateral adenomas, two parathyroid hyperplasias, one adenoma included in the thyroid parenchyma $4.3 \%$. A study of the location of the

Table 2 : Preoperative imaging sensitivity

\begin{tabular}{ll}
\hline & Number of patients (97) \\
\hline $\begin{array}{l}\text { Adenoma localization: } \\
\text { Sensitivity: Positive ultrasonography/ }\end{array}$ & $45 / 53(84.9 \%)$ \\
positive scintigraphy and concordant & \\
$\begin{array}{l}\text { Side localization: } \\
\text { Sensitivity: Positive ultrasonography/ }\end{array}$ & $49 / 53(92.4 \%)$ \\
positive scintigraphy and concordant & \\
$\begin{array}{l}\text { Adenoma localization: } \\
\text { Sensitivity: Positive ultrasonography/ }\end{array}$ & $13 / 21(61.9 \%)$ \\
negative scintigraphy & \\
$\begin{array}{l}\text { Adenoma localization: } \\
\text { Sensitivity: negative ultrasonography/ } \\
\text { positive scintigraphy }\end{array}$ & \\
False positive of imaging & \\
\hline
\end{tabular}

Table 3 : Frozen section examination results

\begin{tabular}{ll}
\hline & Number of patients (97) \\
\hline $\begin{array}{l}\text { Mean duration (in minutes) } \\
\text { Durations distribution }\end{array}$ & $24.1 \pm 8.56(10-55)$ \\
$\quad$ Less than 20 minutes & $42.0 \%$ \\
$\quad$ Between 20 and 30 minutes & $39.2 \%$ \\
$\quad$ Over 30 minutes & $19.4 \%$ \\
Results & \\
$\quad$ Parathyroid adenoma & $85 / 97(87.6 \%)$ \\
$\quad$ Thyroid & $4 / 97(4.1 \%)$ \\
$\quad$ Normal parathyroid & $6 / 97(9.2 \%)$ \\
$\quad$ Hyperplasia & $2 / 97(2.1 \%)$ \\
Confirmation of frozen section & $97 / 97(100 \%)$ \\
examination result from final & \\
anatomopathological examination & \\
\hline
\end{tabular}

lateralization of the adenoma shows a sensitivity of $92.4 \%$ in case of concordant imaging tests. All gland errors on the same side were related to migrated superior adenomas labelled as inferior parathyroid adenomas (Table 3).

Therefore, there were 12 cases $(12.4 \%)$ for which the frozen tissue examination has changed the operating strategy, leading to an exploratory cervicotomy with visualization of the other glands (Table 3). The frozen tissue examination found six normal parathyroid glands $(50 \%)$, four thyroid tissues (33.3\%) and two hyperplastic parathyroid glands $(16.7 \%)$. These two cases of intraoperative diagnosis of hyperplasia were patients who had two concordant imaging examinations with a single location. The frozen tissue examination results thus led to 12 exploratory cervicotomies that helped find 10 adenomas $(83.3 \%)$, including one in the thyroid lobe, and perform two subtotal parathyroidectomies for parathyroid hyperplasia (Table 4).

The mean operating time was $81.3 \pm 36.8$ minutes and the mean duration of the frozen tissue examination was $24.2 \pm 8.6$ minutes.

All frozen tissue examination diagnoses were confirmed during the final anatomopathological examination.

Table 4. Surgical strategy changing

\begin{tabular}{ll}
\hline & Number of patients (97) \\
\hline $\begin{array}{l}\text { False positive imaging result } \\
\text { corrected by per operative surgeon } \\
\text { macroscopical examination with }\end{array}$ & $11 / 23(47.8 \%)$ \\
homolateral adenoma found & \\
$\begin{array}{l}\text { Modification in surgical strategy: } \\
\text { Neck exploration continuation }\end{array}$ & $12 / 23(52.2 \%)$ \\
Homolateral exploration & $12 / 97(12.4 \%)$ \\
$\quad$ Homolateral adenoma & $3 / 12(25 \%)$ \\
Further contralateral exploration & $9 / 12(75 \%)$ \\
$\quad$ Contralateral adenoma & $6 / 12(50 \%)$ \\
$\quad$ Parathyroid hyperplasia & $2 / 12(16.7 \%)$ \\
Intrathyroidal adenoma & $1 / 12(8.3 \%)$ \\
\hline
\end{tabular}


Table 5. Postoperative results

\begin{tabular}{ll}
\hline & Number of patients (97) \\
\hline Mean operative time (in minutes) & $79.5 \pm 36.8(29-210)$ \\
1 day postoperative calcemia (mmol/l) & $2.21 \pm 0.15(2.0-2.63)$ \\
1 month postoperative calcemia & $2.32 \pm 0.12(2.0-2.65)$ \\
$(\mathrm{mmol} / \mathrm{l})$ & \\
1 month postoperative PTH & $82.2 \pm 47.2(21-280)$ \\
1 month cure rate & $97 / 97(100 \%)$ \\
\hline
\end{tabular}

The average corrected serum calcium level on the 1st postoperative day was $2.21 \pm 0.15 \mathrm{mmol} / \mathrm{L}$. The average corrected serum calcium level at 1 month was $2.32 \pm 0.12$ $\mathrm{mmol} / \mathrm{L}$ and the average PTH level was $82.2 \pm 47.2$.

No recurrent laryngeal nerve block or postoperative hypoparathyroidism was noted.

A total of 97 patients were cured in 1 month (normal serum calcium level at 1 month), which means a cure rate of $100 \%$. It should be noted that there was one patient whose corrected serum calcium and PTH at 1 month were $2.65 \mathrm{mmol} / \mathrm{L}$ and $46 \mathrm{pg} / \mathrm{mL}$ respectively, and 2.48 $\mathrm{mmol} / \mathrm{L}$ at 3 months, when rechecked (Table 5).

\section{DISCUSSION}

In our series, 97 patients underwent a minimally invasive surgery. The sensitivity of the preoperative imaging examinations was $84.9 \%$ in the case of concordance, $92 \%$ for the location of the side, $65 \%$ for the scintigraphy alone and $61.9 \%$ for the ultrasound alone. Of the 23 false positive imaging results, 11 were corrected by the surgeon's macroscopic examination and 12 by frozen tissue examination. Two hyperplasias were found. The cure rate at 1 month was $100 \%$.

The exploratory cervicotomy with identification of the four glands remains a standard in the treatment of hyperparathyroidism ${ }^{5}$ with a specific risk of bilateral recurrent laryngeal nerve block and hypoparathyroidism but especially of prolonged surgery and hospitalization period and a longer scar. Finally, for Arnalsteen et al, ${ }^{6}$ the rate of recurrence of the hyperparathyroidism requiring repeat surgery was $4.1 \%$ with increased morbidity ( $9 \%$ hypoparathyroidism) and difficulties during the repeat surgery. ${ }^{7}$

In addition, the average duration of the frozen tissue examination of 24.2 minutes \pm 8.6 proved less important than for repeat PTH assays and did not generate a significant difference in terms of cost (the price of a frozen tissue examination of an anatomical structure sample outside the sampling location is $€ 84$ according to the Classification Commune des Actes Médicaux (CCAM) [Common Classification of Medical Procedures] compared with 4-5 PTH assays. ${ }^{8}$

The intraoperative macroscopic examination of the gland by a trained surgeon helped correct the lack of sensitivity of the imaging tests, since in $47.8 \%$ of cases (11 out of 23), with further ipsilateral exploration, an adenoma was found. Thus parathyroid surgery must be performed by trained surgeons and pathologists in expert centers. ${ }^{1}$

\section{Frozen Tissue Examination}

The frozen tissue examination diagnosis was confirmed in $100 \%$ of cases by the final examination in our series with two cases of sporadic hyperplasia diagnosed intraoperatively.

The cytopathological frozen tissue examination diagnosis is thus feasible in a well-selected population, but remains difficult. ${ }^{9}$ The definitive diagnosis of hyperplasia is even more difficult because of the possible asymmetric and asynchronous progress of the disease and the absence of formal criteria. ${ }^{10}$

The pathologist's expertise ${ }^{1}$ is, therefore, the main factor determining the reliability of this examination, which is, thus, not reproducible in all centers.

\section{Multiple Adenomas}

We did not observe a double adenoma in our well-selected series. However, frozen tissue examination does not help eliminate the risk of multiple adenomas. The frequency of multiple adenomas is estimated at somewhere between $2 \%$ and $4 \%{ }^{11}$ and therefore, justifies for some the routine use of the intraoperative PTH assay. Suliburk JW et a ${ }^{12}$ has shown on 1,020 procedures that it is possible to envisage a minimally invasive approach without the use of intraoperative control with satisfactory reliability of $98 \%$ in case of concordant imaging and that $50 \%$ of the failures relate to double adenomas, i.e., 10 patients $(1 \%)$. Hence, imaging examinations help diagnose multiple adenomas but with lower sensitivity than for a single-gland disease. ${ }^{13}$

\section{Hyperplasia}

In our series, two sporadic hyperplasias were diagnosed intraoperatively. For Vandenbulcke, the incidence of sporadic parathyroid hyperplasia was $2.4 \%{ }^{14}$ In our case, these were two women aged 63 and 80 years with typical primary hyperparathyroidism symptoms with no personal or family history that may have suggested a Multiple Endocrine Neoplasia, whose serum calcium levels were 2.41 and $2.61 \mathrm{mmol} / \mathrm{L}$, and the PTH level was 141 and $120 \mathrm{pg} / \mathrm{mL}$ respectively, without renal failure. It should be noted that urinary calcium was not measured, therefore, a family hypocalciuric hypercalcemia cannot be ruled out. In these two cases, a concordant target was found on the ultrasound and scintigraphy, the reason for which a minimally invasive approach was used. 


\section{Imaging}

The sensitivities of the preoperative imaging examinations in our series are comparable to those found in the literature. It should be noted that not all the examinations have been performed or repeated in our center due to technical problems. As a result, not all scintigraphic examinations have been performed according to the same protocols and the information retained was, therefore, based in some cases on the account of the nuclear medicine physician. The sensitivity of these examinations, to be carried out by trained radiologists and nuclear medicine physicians, ${ }^{15}$ varies in the literature ranging from 60 to $90 \%$ for the scintigraphy and from 60 to $85 \%$ for the ultrasound and reaches $96 \%$ in case of concordance in some studies. ${ }^{16}$ It is, therefore, necessary to strive to obtain concordant imaging examinations by repeating the examinations if necessary or by completing the assessment by a cervical mediastinal thin-slice computed tomography (CT)-scan with contrast agents, using the MIBI SPECT, with three dimensional reconstruction ${ }^{17}$ in order to detect a greater number of patients with multiglandular involvement and, thus, to immediately turn to an exploratory cervicotomy as first-line treatment. The preoperative imaging examinations are, first of all, a cervical ultrasound combined with sestaMIBI, or better, 123I/sestaMIBI dual isotope scintigraphy. ${ }^{15}$ The CT-scan appears to be a second-line examination reserved for inconsistencies of first-line examinations and for the investigation of mediastinal locations with a sensitivity of $88 \%$. For this, millimeter cuts are recommended without injection and then with injection of contrast agent with acquisitions at 45 and 70 seconds. ${ }^{18}$ On the contrary, the scan can be analyzed pre- and intraoperatively by the surgeon. The recent emergence of SPECT/MIBI further improves the sensitivity by around $10 \%$ according to some studies. ${ }^{19}$

\section{Intraoperative Parathyroid Hormone}

The intraoperative PTH assay is recommended by many learned societies ${ }^{20}$ in order to ensure the removal of the diseased gland or glands and thus, cure the patient during the surgical procedure. But the methods are not yet validated. Indeed, there are sensitivity defects of the technique that lead some authors to regularly propose new protocols. Multiple PTH decrease scores have been proposed (Miami, Rome, Vienna, Halle, etc. $)^{21}$ because none is fully satisfactory. Indeed, in the event of multiglandular disease, the intraoperative PTH assay proves less reliable, ${ }^{22,23}$ with inconsistent and difficult to interpret kinetics and requires an experienced surgeon and the need for repeat assays taking up to 30 or even 60 minutes. ${ }^{24}$
Due to the variability in the kinetics of decrease in PTH levels depending on the patient, the disease, the number of glands involved, etc., the sensitivity of this examination is $97 \% .{ }^{25,26}$

The $100 \%$ cure rate of the population treated by minimally invasive approach in our series is satisfactory and comparable to the results provided in series systematically using the intraoperative PTH assay. ${ }^{27}$

Finally, we have also described the intratissue PTH assay, which provides a rapid and certain diagnosis of the nature of the biopsied parathyroid lesion but also a reliable diagnosis of adenoma for intratissuePTH values over $2,000 \mathrm{pg} / \mathrm{mL}^{28-30}$

\section{CONCLUSION}

Although the exploratory cervicotomy of the four glands remains a standard, parathyroid surgery by minimally invasive approach is less morbid and reduces the operating time, the length of hospital stay, and the complication rates in the event of repeat surgery. The frozen tissue examination of the parathyroidectomy specimen in hyperparathyroidism surgery appears as an effective and intraoperatively reproducible tool in trained teams and in well-selected populations, because it is available in real time and thus, enables the surgeon to correct a number of false positive results of the preoperative imaging and the macroscopic assessments performed by the surgeon. The main obstacles to this technique are the pathologist's expertise and the very rare risk of multiple adenomas, which is reduced by a comprehensive preoperative imaging assessment which must also be analyzed by the surgeon.

\section{REFERENCES}

1. Udelsman R, Åkerström G, Biagini C, Duh QY, Miccoli P, Niederle B, Tonelli F.. The surgical management of asymptomatic primary hyperparathyroidism : proceedings of the Fourth International Workshop. J Clin Endocrinol Metab 2014 Oct ;99(10): 3595-3606

2. Miccoli P, Materazzi G, Baggiani A, Miccoli M. Mini-invasive video-assisted surgery of the thyroid and parathyroid glands: a 2011 update. J Endocrinol Invest 2011 Jun;34(6):473-480.

3. Henry JF, Sebag F, Ippolito G. Endoscopic parathyroidectomy through a lateral approach. J Chir (Paris) 2008 SepOct;145(5):470-474.

4. Pizzolitto S, Piemonte M. Intraoperative extemporaneous examination of the parathyroid gland: what is the role of the pathologist in parathyroid pathology? Acta Otorhinolaryngol Ital 1991. Jul-Aug;11(4):395-404.

5. Clark OH, Duh QY. Primary hyperparathyroidism. A surgical perspective. Endocrinol Metab Clin North Am 1989 Sep;18(3):701-714.

6. Arnalsteen L, Quievreux JL, Huglo D, Pattou F, Carnaille B, Proye C. Reoperation for persistent or recurrent primary hyperparathyroidism. Seventy-seven cases among 1888 operated patients. Ann Chir 2004 May;129(4):224-231 
7. Henry JF. Reoperation for primary hyperparathyroidism: tips and tricks. Langenbecks Arch Surg 2010 Feb ;395(2):103-109

8. Morris LF, Zanocco K, Ituarte PH, Ro K, Duh QY, Sturgeon C, Yeh MW. The value of intraoperative parathyroid hormone monitoring in localized primary hyperparthyroidism: a cost analysis. Ann Surg Oncol 2010 Mar;17(3):679-685

9. Grimelius L. Akerström G, Bondeson L, Juhlin C, Johansson H, Ljunghall S, Rastad J. The role of the pathologist in diagnosis and surgical decision making in hyperparathyroidism. World J Surg 1991 Nov-Dec;15(6) :698-705

10. Saxe AW, Baier R, Tesluk H, Toreson W. The role of the pathologist in the surgical treatment of hyperparathyroidism. Surg Gynecol Obst 1985 Aug;16(2):101-105.

11. Summers GW. Parathyroid exploration. A review of 125 cases. Arch Otolaryngol Head Neck Surg 1991;117:1237-1241.

12. Suliburk JW, Sywak MS, Sidhu SB, Delbridge LW. 1000 minimally invasive parathyroidectomies without intra-operative parathyroid hormone measurement: lessons learned. ANZ J Surg 2011 May;81(5):362-365.

13. Wimmer G, Profanter C, Kovacs P, Sieb M, Gabriel M, Putzer D, Bale R, Margreiter R, Prommegger R. CT-MIBI-SPECT image fusion predicts multiglandular disease in hyperparathyroidism. Langenbecks Arch Surg 2010 Jan;395(1):73-80.

14. Vandenbulcke O, Delaere P, Vander Poorten V, Debruyne F. Incidence of multiglandular disease in sporadic primary hyperparathyroidism. B-ENT 2014;10(1):1-6.

15. Philippon M, Guerin C, Taieb D, Vaillant J, Morange I, Brue T, Conte-Devolx B, Henry JF, Slotema E, Sebag F, et al. Bilateral neck exploration in patients with primary hyperparathyroidism and discordant imaging results: a single-centre study. Eur J Endocrinol 2014 Apr 10;170(5):719-725.

16. Arici $\mathrm{C}$, Cheah WK, Ituarte $\mathrm{PH}$, Morita E, Lynch TC, Siperstein AE, Duh QY, Clark OH. Can localization studies be used to direct focused parathyroid operations? Surgery 2001 Jun;129(6):720-729.

17. D'Agostino, Diana M, Vix M, Nicolau S, Soler L, Bourhala K, Hassler S, Wu HS, Marescaux J. Three-dimensional metabolic and radiologic gathered evaluation using VR-RENDER fusion: a novel tool to enhance accuracy in the localization of parathyroid adenomas. World J Surg 2013 Jul;37(7):1618-1625.

18. Marmin C, Toledano M, LemaireS, Boury S, MordonS, ErnstO. Computed tomography of the parathyroids: the value of density measurements to distinguish between parathyroid adenomas of the lymph nodes and the thyroid parenchyma. Diagn Interv Imaging 2012 Jul;93(7-8):597-603.

19. Heiba SI, Jiang M, Rivera J, Genden E, Inabnet W 3rd, Machac J, Kostakoglu L. Direct comparison of neck pinhole dual-tracer and dual-phase MIBI accuracies with and without SPECT/
CT for parathyroid adenoma detection and localization. Clin Nucl Med 2015 Jun;40(6):476-482.

20. Inabnet WB. Intraoperative parathyroid hormone monitoring. World J Surg 2004 Dec;28(12):1212-1215.

21. Papier A, Kenig J, Barczynski M. Evaluation of different intraoperative iPTH assay criteria in monitoring of minimally invasive parathyroidectomy for primary hyperparathyroidism. Przegl Lek 2014;71(1):14-18.

22. Karakousis GC, Han D, Kelz RR, Nemani D, Karamacharya J, Roses R, Gimotty PA, Fraker DL. Interpretation of intraoperativePTHchangesin patientswithmulti-glandularprimary hyperparathyroidism (pHPT). Surgery 2007 Dec;142(6): 845-850;

23. Thakur A, Sebag F, Slotema E, Ippolito G, Taïeb D, Henry JF. Significance of biochemical parameters in differentiating uniglandular from multiglandular disease and limiting use of intraoperative parathormone assay. World J Surg 2009 Jun;33(6):1219-1223.

24. Calò PG,Pisano G, Loi G,MedasF, Barca L, Atzeni M,Nicolosi A. Intraoperative parathyroid hormone assay during focused parathyroidectomy: the importance of 20 minutes measurement. BMC Surg 2013 Sep 18;13:36.

25. Calo PG, Pisano G, Tatti A, Medas F, Boi F, MariottiS, Nicolosi A. Intraoperative parathyroid hormone assay during focused parathyroidectomy for primary hyperparathyroidism: is it really mandatory? Minerva Chir 2012 Aug;67(4):337-342.

26. Vignali E, Picone A, Materazzi G, SteffeS, Berti P, Cianferotti L, Cetani F, Ambrogini E, Miccoli P, Pinchera A, et al. A quick intraoperative parathyroid hormone assay in the surgical management of patients with primary hyperparathyroidism: a study of 206 consecutive cases. Eur J Endocrinol 2002 Jun;146(6):783-788.

27. Day KM, Elsayed M, Monchik JM. No need to abandon focused unilateral exploration for primary hyperparathyroidism with intraoperative monitoring of intact parathyroid hormone. J Am Coll Surg 2015 Aug;221(2):518-523.

28. Chan RK, Ibrahim SI, Pil P, Tanasijevic M, Moore FD. Validation of a method to replace frozen section during parathyroid exploration by using the rapid parathyroid hormone assay on parathyroid aspirates. Arch Surg 2005 Apr;140(4):371-373.

29. Perrier ND, Ituarte $P$, Kikuchi $S$, Siperstein AE, Duh QY, Clark $\mathrm{OH}$, Gielow R, Hamill T. Intraoperative parathyroid aspiration and parathyroid hormone assay as an alternative to frozen section for tissue identification. World J Surg 2000 Nov;24(11):1319-1322.

30. Kirkby-Bott J, Carnaille B. et al. Experience of the reliability of intraoperative sampling of tissue $\mathrm{PTH}$ in parathyroid surgery: letter to the editor. World J Surg 2010 Sep;34(9):2254. 